\title{
The crystallographic phase transition for a ferric thiosemicarbazone spin crossover complex studied by X-ray powder diffraction $\dagger$
}

\author{
Sébastien Floquet, ${ }^{a b}$ Nathalie Guillou, ${ }^{b}$ Philippe Négrier, ${ }^{c}$ Eric Rivière $^{a}$ and \\ Marie-Laure Boillot*a
}

The crystal structure of a spin transition compound, namely the thiosemicarbazone ferric complex $\mathrm{Li}\left[\mathrm{Fe}(5 \mathrm{BrThsa})_{2}\right] \cdot \mathrm{H}_{2} \mathrm{O}$, was solved from powder $\mathrm{X}$ ray diffraction data at temperatures where the high spin $(373 \mathrm{~K})$ and low spin $(150 \mathrm{~K})$ phases prevail. The methodology is based on traditional approaches (direct methods) combined with direct space strategy. Both phases crystallise in the monoclinic system $P 2_{1} / c$. At $373 \mathrm{~K}$, the characteristics of the $\left[\mathrm{FeN}_{2} \mathrm{O}_{2} \mathrm{~S}_{2}\right]$ coordination core are consistent with those reported for high spin iron(III) thiosemicarbazone complexes: a distorted coordination polyhedron and non equivalent metal ligand bond lengths. When the temperature is reduced to $150 \mathrm{~K}$, a decrease of the $\beta$ angle from $c a$. $101^{\circ}(373 \mathrm{~K})$ to $c a .90^{\circ}(150 \mathrm{~K})$ is the only major modification of the cell parameters. The low spin molecular structure reveals significant differences in bond lengths and bond angles compared to the high spin structure. Finally, an extended hydrogen bond network is implicated in the cooperative phase transition, as supported by strong intermolecular contacts between the ferric complexes and the water molecules and the crystallographic phase transition is associated with pronounced lattice reorganization.

\section{Introduction}

The spin crossover phenomenon, first reported by Cambi et al. with $\operatorname{tris}\left(N, N\right.$ dialkyl dithio carbamato)iron(III) compounds, ${ }^{1}$ has been later characterized for numerous $3 \mathrm{~d}^{4} 3 \mathrm{~d}^{7}$ transition metal complexes. This field of molecular magnetism ${ }^{2}$ has been investigated extensively and provided spectacular examples of molecular bistability. Cooperative spin transitions and occur rence of hysteresis effects, described mainly for ferrous com pounds, ${ }^{3}$ are of interest for material science, both from a fundamental and an applied standpoint. For a majority of ferric systems, thermally activated spin equilibria have been also reported, ${ }^{4}$ and their roles in biological systems are of prime importance. 5

We recently reported a cooperative $S \quad 1 / 2 \leftrightarrow S \quad 5 / 2$ spin conversion process with hysteretic behavior in a ferric thiosemicarbazone complex, $\mathrm{Li}\left[\mathrm{Fe}(5 \mathrm{BrThsa})_{2}\right] \cdot \mathrm{H}_{2} \mathrm{O} \quad\left(\mathrm{H}_{2}\right.$ 5BrThsa being the 5 bromosalicylaldehyde thiosemicarba zone, see Chart 1). ${ }^{6}$

This compound belongs to a family of ferric complexes that provides interesting examples of cooperative processes. ${ }^{7-14}$

\footnotetext{
${ }^{a}$ ICMMO, Equipe de Chimie Inorganique, UMR 8182, Université Paris Sud,91400 Orsay, France.E mail:mboillot@icmo.u psud.fr

${ }^{b}$ Institut Lavoisier de Versailles, UMR 8180, Université de Versailles, 45 avenue des Etats Unis, 78035 Versailles, France.

E mail: sebastien.floquet@uvsq.fr

${ }^{c}$ Centre de Physique Moléculaire Optique et Hertzienne, UMR 5798,

Université Bordeaux I, Talence, France
}

When isolated as a water solvate, the title complex, $\mathrm{Li}\left[\mathrm{Fe}(5 \mathrm{BrThsa})_{2}\right] \cdot \mathrm{H}_{2} \mathrm{O}$, undergoes a discontinuous spin tran sition with a rather broad hysteresis $(\Delta T \quad 39 \mathrm{~K})$ centred near room temperature (see Fig. 1). In contrast, the anhydrous material displays only a continuous transition. ${ }^{8}$ The high spin (HS) $\leftrightarrow$ low spin (LS) conversion of $\mathrm{Li}\left[\mathrm{Fe}(5 \mathrm{BrThsa})_{2}\right] \cdot \mathrm{H}_{2} \mathrm{O}$ is associated with lattice reorganization: powder $\mathrm{X}$ ray diffrac tion investigations have shown the occurrence of a crystal lographic first order phase transition coupled to the electronic spin state transition. ${ }^{6,14}$ On the basis of temperature depen dent IR measurements, it has been proposed that the phase transformation is associated with the modification of a hydro gen bond network (see Fig. S1 in the ESI $\dagger$ ). In the absence of a quality crystal for single crystal $\mathrm{X}$ ray diffraction, we consid ered analysing the structural properties by powder $\mathrm{X}$ ray diffraction techniques. As shown for a number of materials over the past ten years, this technique is a powerful tool that provides very valuable structural characterisations. ${ }^{15}$

We present here the powder structural resolution of the high and low temperature phases of $\mathrm{Li}\left[\mathrm{Fe}(5 \mathrm{BrThsa})_{2}\right] \cdot \mathrm{H}_{2} \mathrm{O}$ in order to (i) determine the molecular structure of the anionic ferric complex (ii) analyze packing parameters associated with the discontinuous spin transition and the concomitant phase transition and (iii) identify the intermolecular contacts<smiles>N/C(S)=N/N=C/c1cc(Br)ccc1O</smiles>

Chart 1 5BrThsa ${ }^{2-}$ ligand. 


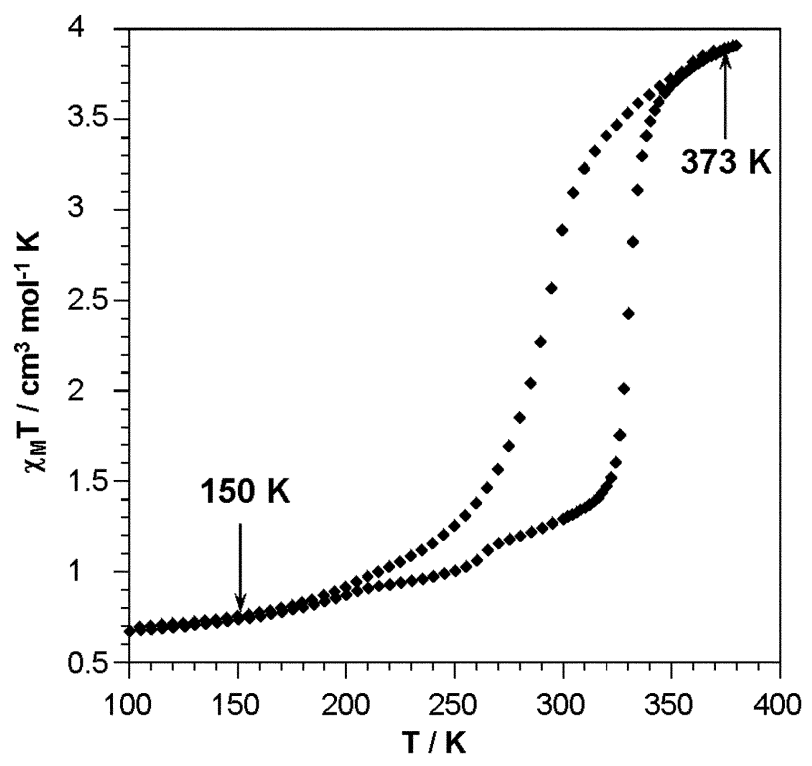

Fig. 1 Temperature dependence of the $\chi_{\mathrm{M}} T$ product for $\mathrm{Li}[\mathrm{Fe}$ (5BrThsa) $\left.)_{2}\right] \cdot \mathrm{H}_{2} \mathrm{O}$.

between complexes which are the origin of the large asym metric hysteretic loop of this compound.

\section{Results and discussion}

\section{Magnetic measurements}

In Fig. 1 is shown the temperature dependence of the $\chi_{\mathrm{M}} T$ product $\left(\chi_{\mathrm{M}}\right.$ being the molar magnetic susceptibility) of $\mathrm{Li}\left[\mathrm{Fe}(5 \mathrm{BrThsa})_{2}\right] \cdot \mathrm{H}_{2} \mathrm{O}$. The discontinuous $S \quad 1 / 2 \leftrightarrow S$ $5 / 2$ transition is associated with a broad asymmetric hysteresis loop $\left(T_{\mathrm{C}} \downarrow \quad 292 \mathrm{~K}\right.$ and $\left.T_{\mathrm{C}} \uparrow \quad 329 \mathrm{~K}\right)$. The $\chi_{\mathrm{M}} T$ values of $0.63 \mathrm{~cm}^{3} \mathrm{~mol}^{-1} \mathrm{~K}$ at $50 \mathrm{~K}$ and $3.91 \mathrm{~cm}^{3} \mathrm{~mol}^{-1} \mathrm{~K}$ at $383 \mathrm{~K}$ correspond to $3 \%$ and $88 \%$ fractions of HS species, respec tively, which indicates that the transition is near complete.

The hysteretic behaviour stems from a first order crystal lographic phase transition occurring upon spin crossover, as evidenced by DSC and routine XDP measurements. ${ }^{6}$ More over, the very small step detected near $260 \mathrm{~K}$ in the heating curve (see Fig. 1) was previously assigned to an amorphous phase of $\mathrm{Li}\left[\mathrm{Fe}(5 \mathrm{BrThsa})_{2}\right] \cdot \mathrm{H}_{2} \mathrm{O}$, which was not evidenced by $\mathrm{X}$ ray powder diffraction.

To conclude, the magnetic behaviour of $\mathrm{Li}[\mathrm{Fe}$ $\left.(5 \mathrm{BrThsa})_{2}\right] \cdot \mathrm{H}_{2} \mathrm{O}$ clearly shows the dramatic influence of a solvent molecule as the solvent free compound exhibits a continuous spin crossover process. ${ }^{8}$

For instance, while a number of ferrous complexes exhibit a LIESST effect, very few ferric complexes are known to possess light induced properties. ${ }^{16}$ Investigation of the LIESST effect has been carried out on $\mathrm{Li}\left[\mathrm{Fe}(5 \mathrm{BrThsa})_{2}\right] \cdot \mathrm{H}_{2} \mathrm{O}$ at low tem perature $(10 \mathrm{~K})$ and various excitation wavelengths. Unfortu nately, no significant light induced conversion of LS complexes to the metastable HS state was evidenced. It's well known that ferric complexes exhibit fast relaxation processes of the metastable HS state. It's thus difficult to observe the LIESST effect for these complexes. Moreover, the colour of
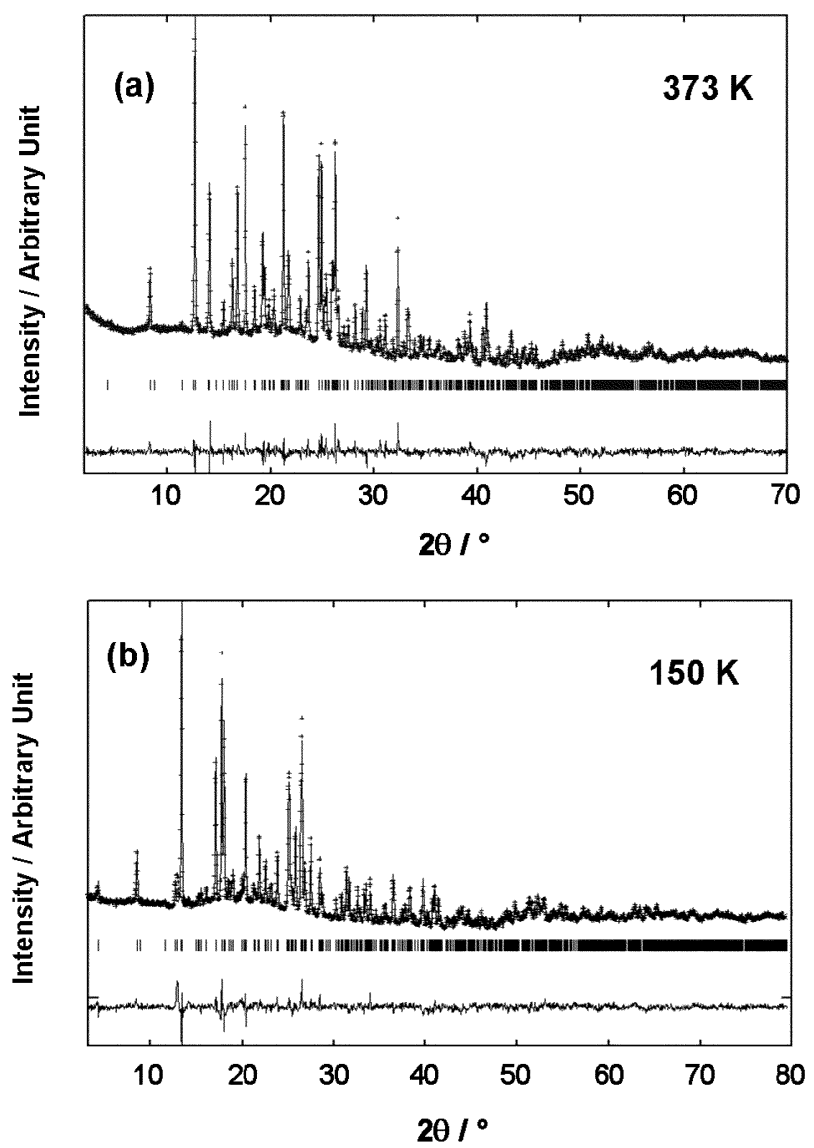

Fig. 2 Final Rietveld plots of the HS phase (a) and LS phase (b). The experimental data are shown by dots and the calculated pattern by a solid line. Difference curves are represented below; vertical bars mark the Bragg reflection positions.

our compound (dark brown to black) is probably not favour able to obtain a satisfactory excitation of the sample.

\section{HS structure at $373 \mathrm{~K}$}

Fig. 2a shows the final Rietveld refinement of the $373 \mathrm{~K}$ XDP of $\mathrm{Li}\left[\mathrm{Fe}(5 \mathrm{BrThsa})_{2}\right] \cdot \mathrm{H}_{2} \mathrm{O}$. This compound crystallises in the monoclinic system $P 2_{1} / c$, with cell parameters given in Table 1 and selected angles and distances in Tables 2 and 3, respec tively. The molecular structure refinement was carried out by letting bond angles free and allowing bond distances to vary slightly around mean values reported in the literature for similar HS ferric complexes. Analysis of the results is then based on the bond angles, whose values strongly depend on the metal ion spin states. ${ }^{14,17}$

The molecular structure of $\left[\mathrm{Fe}(5 \mathrm{BrThsa})_{2}\right]^{-}$at $373 \mathrm{~K}$ is given in Fig. 3. The two tridentate ligands are placed around the metal ion in a meridional fashion. The coordination $\left[\mathrm{FeO}_{2} \mathrm{~N}_{2} \mathrm{~S}_{2}\right]$ core consists of two oxygen atoms (phenolate), two nitrogen atoms (imine) in trans disposition, and two sulfur atoms. The distortion of the coordination polyhedron is evidenced by bond angles deviating significantly from $90^{\circ}$ (see Table 2 and Fig. S2a in the ESI $\dagger$ ). It results from the constraints imposed by the interconnected five and six mem bered chelate cycles and the non equivalent metal ligand 
Table 1 Crystallographic data for $\mathrm{Li}\left[\mathrm{Fe}(5 \mathrm{BrThsa})_{2}\right] \cdot \mathrm{H}_{2} \mathrm{O}$ at 373 and $150 \mathrm{~K}$

\begin{tabular}{|c|c|c|}
\hline Formula & \multicolumn{2}{|c|}{$\mathrm{LiFe}\left(\mathrm{BrC}_{8} \mathrm{H}_{6} \mathrm{~N}_{3} \mathrm{OS}\right)_{2} \cdot \mathrm{H}_{2} \mathrm{O}$} \\
\hline Chemical formula weight $/ \mathrm{g} \mathrm{mol}^{-1}$ & 625.05 & \\
\hline$T / \mathrm{K}$ & 373 & 150 \\
\hline Calculated density $/ \mathrm{g} \mathrm{cm}^{-3}$ & 1.849 & 1.981 \\
\hline Crystal system & Monoclinic & Monoclinic \\
\hline Space group & $P 2_{1} / c$ & $P 2_{1} / c$ \\
\hline$a / \AA$ & $21.554(1)$ & $20.715(2)$ \\
\hline$b / \AA$ & $11.479(1)$ & $11.397(1)$ \\
\hline$c / \AA$ & $8.943(1)$ & $8.880(1)$ \\
\hline$\beta /^{\circ}$ & $101.235(2)$ & $90.258(2)$ \\
\hline$V / \AA^{3}$ & $2170.2(2)$ & 2096.5(3) \\
\hline$M_{20}$ & 16 & 19 \\
\hline$F_{20}$ & $37(0.0092 ; 59)$ & $42(0.0066 ; 73)$ \\
\hline$Z$ & 4 & 4 \\
\hline Radiation & $\mathrm{Cu} \mathrm{K} \alpha_{1}$ & $\mathrm{Cu} \mathrm{K} \alpha_{1}$ \\
\hline $2 \theta \mathrm{range}^{\circ}$ & $2.17 \quad 70$ & 3.1879 .5 \\
\hline No. reflections & 946 & 1253 \\
\hline No. atoms & 30 & 30 \\
\hline No. structural parameters & 91 & 91 \\
\hline$R_{\mathrm{P}}, R_{\mathrm{WP}}$ & $0.019,0.025$ & $0.022,0.031$ \\
\hline$R_{\mathrm{I}}, R_{\mathrm{F}}$ & $0.082,0.069$ & $0.094,0.063$ \\
\hline$R_{\exp }$ & 0.009 & 0.010 \\
\hline
\end{tabular}

bonds (see selected data in Table 3). The twelve polyhedron angles of $\left[\mathrm{Fe}(5 \mathrm{BrThsa})_{2}\right]^{-}$at $373 \mathrm{~K}$ are close to those reported for the HS ferric complex $\mathrm{Cs}\left[\mathrm{Fe}(\mathrm{Thsa})_{2}\right]^{9}$ (see Table S1 in the ESI $\dagger)$.

The molecular characteristics of the HS species being de termined, packing and intermolecular interactions can be analysed in order to identify structural parameters favouring the cooperative interactions, hydrogen bonding or $\pi$ stacking interactions. ${ }^{16,18}$ Fig. 4a displays the molecular packing along the $b$ axis. The complexes are organised in layers that are parallel to the $b c$ plane and separated by the hydrophobic component of the ligand (bromo substituted aromatic rings). Within the $b c$ planes, a frame of metal ions separated by 7.22 , 7.34 and $8.94 \AA$ is observed. The inter plane distances are alternatively equal to 10.55 and $11.07 \AA$. No $\pi$ stacking interaction can be identified in the HS lattice. In Table 4 are reported the interatomic distances that are smaller than the sum of the van der Waals radii. The $\mathrm{O}(\mathrm{w} 1)$ oxygen atom of $\mathrm{H}_{2} \mathrm{O}$ is involved in moderate intermolecular contacts with the

Table 2 Selected angles $\left({ }^{\circ}\right)$ for $\mathrm{Li}\left[\mathrm{Fe}(5 \mathrm{BrThsa})_{2}\right] \cdot \mathrm{H}_{2} \mathrm{O}$ at 373 and $150 \mathrm{~K}$

\begin{tabular}{lrr}
\hline$T / \mathrm{K}$ & 373 & 150 \\
\hline $\mathrm{O}(1) \mathrm{FeO}(2)$ & $76(2)$ & $81(2)$ \\
$\mathrm{O}(1) \mathrm{FeS}(2)$ & $101(2)$ & $92(2)$ \\
$\mathrm{O}(1) \mathrm{FeN}(11)$ & $83(2)$ & $88(2)$ \\
$\mathrm{O}(1) \mathrm{FeN}(21)$ & $110(2)$ & $96(2)$ \\
$\mathrm{O}(2) \mathrm{FeS}(1)$ & $94(1)$ & $99(2)$ \\
$\mathrm{O}(2) \mathrm{FeN}(11)$ & $107(2)$ & $97(2)$ \\
$\mathrm{O}(2) \mathrm{FeN}(21)$ & $81(2)$ & $84(2)$ \\
$\mathrm{S}(1) \mathrm{FeS}(2)$ & $97(1)$ & $90(1)$ \\
$\mathrm{S}(1) \mathrm{FeN}(11)$ & $80(2)$ & $83(2)$ \\
$\mathrm{S}(1) \mathrm{FeN}(21)$ & $89(1)$ & $94(2)$ \\
$\mathrm{S}(2) \mathrm{FeN}(11)$ & $94(1)$ & $93(2)$ \\
$\mathrm{S}(2) \mathrm{FeN}(21)$ & $80(1)$ & $86(2)$ \\
$\mathrm{O}(1) \mathrm{FeS}(1)$ & $156(2)$ & $171(2)$ \\
$\mathrm{O}(2) \mathrm{FeS}(2)$ & $158(2)$ & $167(2)$ \\
$\mathrm{N}(11) \mathrm{FeN}(21)$ & $166(2)$ & $178(2)$ \\
\hline
\end{tabular}

Table 3 Selected bond lengths $(\AA)$ for $\mathrm{Li}\left[\mathrm{Fe}(5 \mathrm{BrThsa})_{2}\right] \cdot \mathrm{H}_{2} \mathrm{O}$ at 373 and $150 \mathrm{~K}$

\begin{tabular}{lll}
\hline$T / \mathrm{K}$ & 373 & 150 \\
\hline Fe S $(1)$ & $2.35(2)$ & $2.24(2)$ \\
Fe S(2) & $2.35(2)$ & $2.26(2)$ \\
Fe O(1) & $1.93(3)$ & $1.94(3)$ \\
Fe O (2) & $1.97(3)$ & $1.93(3)$ \\
Fe N(11) & $2.18(2)$ & $1.98(2)$ \\
Fe N $(21)$ & $2.16(2)$ & $1.99(2)$ \\
\hline
\end{tabular}

$\mathrm{N}(12)$ nitrogen atom of the $\mathrm{N} \mathrm{N}$ group (2.91(5) $\AA$ ) and the $\mathrm{O}(2)$ and $\mathrm{O}(1)$ phenolate oxygen atoms (2.99(5) and 3.07(5) $\AA$, respectively). Other intermolecular contacts are also observed: $\mathrm{N}(13) \cdots \mathrm{Br}(2) \quad 3.25(5) \AA, \mathrm{N}(23) \cdots \mathrm{O}(1) \quad 3.09(5) \AA$, and $\mathrm{N}(23) \cdots \operatorname{Br}(1) \quad 3.61(5) \AA$. Although the nature of these interactions (van der Waals contacts, hydrogen bonds) cannot be identified confidently, the distance between $\mathrm{O}_{\mathrm{w}}$ and $\mathrm{N}_{\text {amine }}$ atoms strongly suggests the existence of hydrogen bonds, a feature already pointed out by IR measurements ${ }^{6,14}$ (see Fig. $\mathrm{S} 1$ in the $\mathrm{ESI} \dagger$ ). Note that the strongest intermolecular con tacts are localised in the molecular planes that are parallel to $b c$ planes (see Fig. 5), whereas the weakest interactions are observed between consecutive planes.

\section{LS structure at $150 \mathrm{~K}$}

Fig. $2 \mathrm{~b}$ shows the final refinement of the XDP at $150 \mathrm{~K}$. This crystal structure (pseudo orthorhombic system) is similar to that of $\mathrm{NH}_{4}\left[\mathrm{Fe}(5 \mathrm{BrThsa})_{2}\right]^{10}$ and $\mathrm{NH}_{4}\left[\mathrm{Fe}(5 \mathrm{ClThsa})_{2}\right]^{11}$ (orthorhombic systems, see Table S2 in the ESI $\dagger$ ). The space group remains $P 2_{1} / c$ (Table 1 ), despite the occurrence of a crystallographic phase transition, as characterized by DSC and powder XDP studies. ${ }^{6}$ Both the cell parameters and molecular packing show dramatic changes upon temperature decrease (Fig. 4b). The decrease of $\beta$ from $101.2^{\circ}$ at $373 \mathrm{~K}$ to $90.2^{\circ}$ at $150 \mathrm{~K}$ is associated with changes of the complex

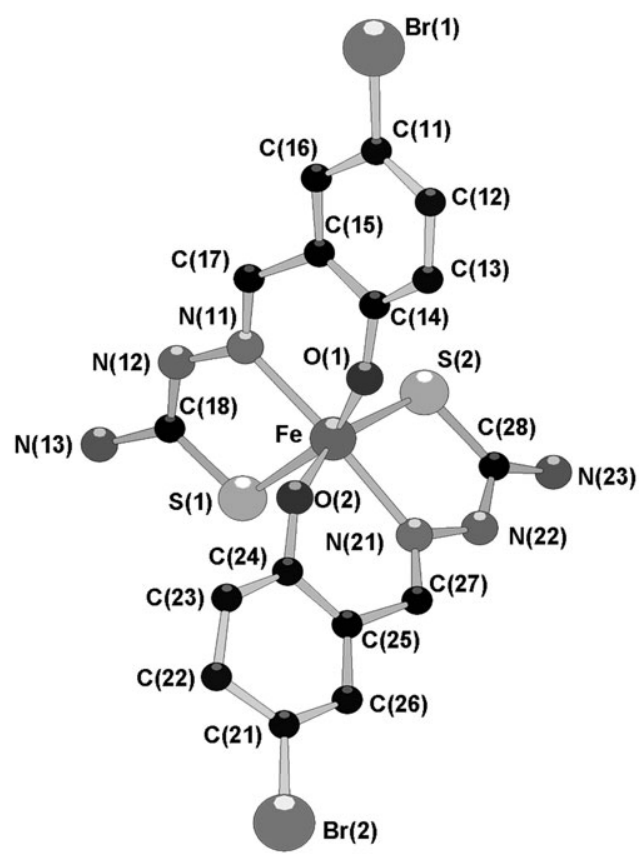

Fig. 3 Structure of the $\left[\mathrm{Fe}(5 \mathrm{BrThsa})_{2}\right]^{-}$anion at $373 \mathrm{~K}$. 


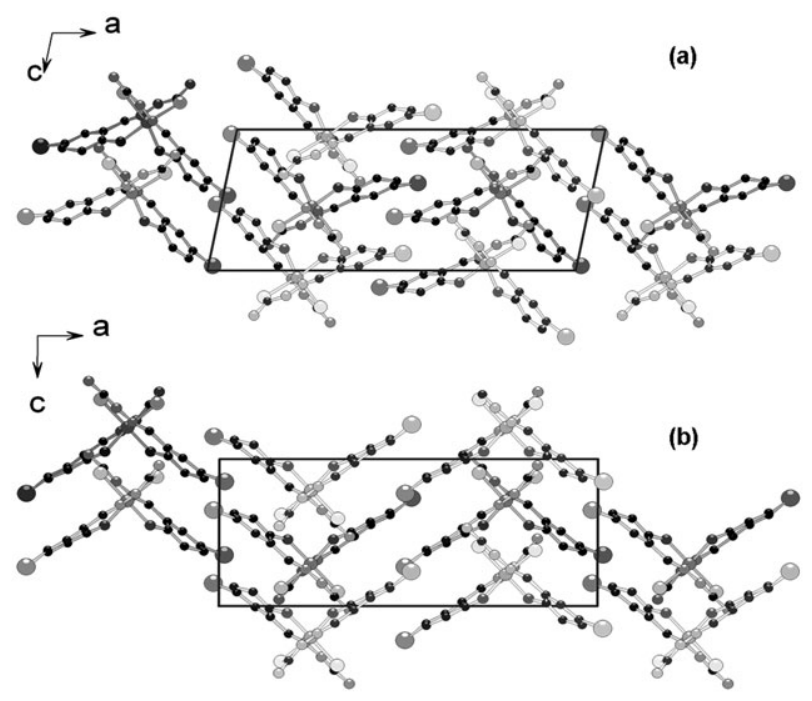

Fig. 4 Comparison of unit cells of HS (a) and LS (b) phases along the $b$ axis. Water molecules have been omitted for clarity.

coordinates in the unit cell and with different positions of the heavy atoms in both phases. These observations account for the differences shown in Fig. 2a and b between the high and low temperature XDP.

The decrease in the unit cell volume from 2170.2(2) $\AA^{3}$ at $373 \mathrm{~K}$ to $2096.5(3) \AA^{3}$ at $150 \mathrm{~K}$ corresponds to a $c a$. $18.5 \AA^{3}$ volume variation per formula unit $\left(\begin{array}{ll}Z & 4\end{array}\right)$. This rather small value corresponds to both lattice thermal contraction and spin crossover. We note that the $c a .3 .5 \%$ relative variation of the unit cell volume upon spin change is of same magnitude to values reported for iron(II) and iron(III) spin crossover com plexes. ${ }^{17}$

The HS to LS change of the metal ion is associated with a net reorganization of the molecular structure. Consistent with literature reports, ${ }^{17,19}$ the coordination angles become closer to $90^{\circ}$ and the distortion of the pseudo octahedral $\left[\mathrm{FeN}_{2} \mathrm{O}_{2} \mathrm{~S}_{2}\right]$ core is reduced at lower temperature (see Fig. S2b and Tables 2 and 3). In addition, we note a reasonable agreement between the polyhedron angles of $\mathrm{Li}\left[\mathrm{Fe}(5 \mathrm{BrThsa})_{2}\right] \cdot \mathrm{H}_{2} \mathrm{O}$ and the values reported by Ryabova et al. for similar LS species ${ }^{10-12}$ (see Table S1 in the ESI $\dagger$ ).

In contrast to the moderate variation of the unit cell volume, drastic changes of the packing and intermolecular interactions occur over the phase transition (see Table 4 and

Table 4 Selected distances $(\AA)$ corresponding to intermolecular con tacts in $\mathrm{Li}\left[\mathrm{Fe}(5 \mathrm{BrThsa})_{2}\right] \cdot \mathrm{H}_{2} \mathrm{O}$ at 373 and $150 \mathrm{~K}$. Values in brackets are given for comparison

\begin{tabular}{|c|c|c|}
\hline$T / \mathrm{K}$ & 373 & 150 \\
\hline $\mathrm{O}(\mathrm{w} 1) \mathrm{N}(12)$ & $2.91(5)$ & $(3.53(5))$ \\
\hline $\mathrm{O}(\mathrm{w} 1) \mathrm{N}(22)$ & $(3.33(5))$ & $2.71(5)$ \\
\hline $\mathrm{O}(\mathrm{w} 1) \mathrm{O}(1)$ & $3.07(5)$ & $3.01(5)$ \\
\hline $\mathrm{O}(\mathrm{w} 1) \mathrm{O}(2)$ & $2.99(5)$ & $3.00(5)$ \\
\hline $\mathrm{N}(13) \mathrm{O}(2)$ & $(3.41(5))$ & $3.23(5)$ \\
\hline $\mathrm{N}(13) \operatorname{Br}(2)$ & $3.25(5)$ & $3.53(5)$ \\
\hline $\mathrm{N}(23) \mathrm{O}(1)$ & $3.09(5)$ & $2.65(5)$ \\
\hline $\mathrm{N}(23) \operatorname{Br}(1)$ & $3.61(5)$ & $(3.83(5))$ \\
\hline
\end{tabular}

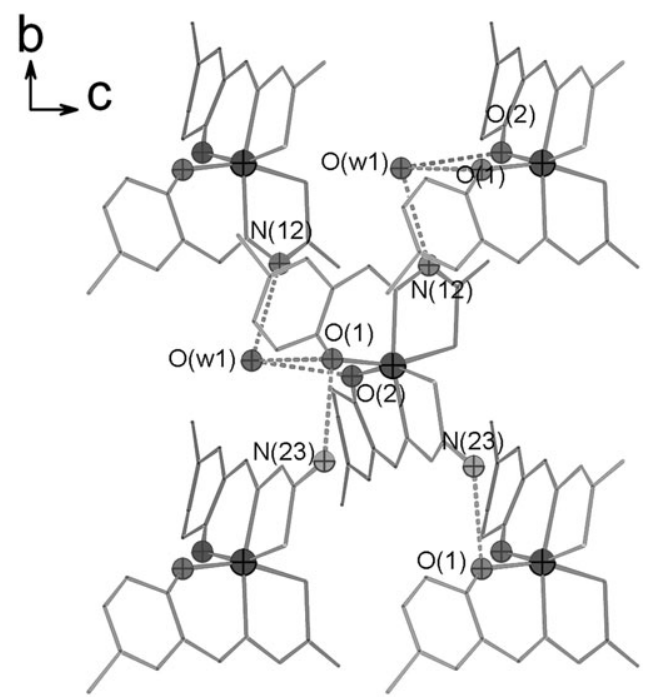

Fig. 5 Strongest intermolecular contacts between complexes at $373 \mathrm{~K}$.

Fig. 4 6). As described above, the molecular packing consists of layers of ferric complexes (in $b c$ plane). Within each layer, the ferric complexes are closely packed with alignments of metal ions alternately separated by 7.13 and $7.31 \AA$. The different planes containing the ferric complexes are spaced along $a$ axis by $c a .11 .33$ and $10.74 \AA$. The intermolecular contacts, mainly observed in the $b c$ planes, differ from those characterised in the high temperature phase. Strong interac tions are observed between oxygen and nitrogen atoms: for example between the phenolate $\mathrm{O}(1)$ and amine $\mathrm{N}(23)$ atoms, $\mathrm{O}(1) \cdots \mathrm{N}(23) \quad 2.65(5) \AA$, and between the water $\mathrm{O}(\mathrm{w} 1)$ and imine $\mathrm{N}(22)$ atoms, $\mathrm{O}(\mathrm{w} 1) \cdots \mathrm{N}(22) \quad 2.71(5) \AA$ (Fig. 6). In parallel, the intermolecular contacts between some $\mathrm{N}$ and $\mathrm{Br}$ atoms decrease: $\mathrm{N}(13) \cdots \mathrm{Br}(2) \quad 3.25(5) \AA(373 \mathrm{~K}), 3.53(5) \AA$ $(150 \mathrm{~K})$ and $\mathrm{N}(23) \cdots \operatorname{Br}(1) \quad 3.61(5) \AA(373 \mathrm{~K}), 3.83(5) \AA$ (150 K).

Different features can be inferred from this set of observa tions. A modulation of the electronic density on the phenolate

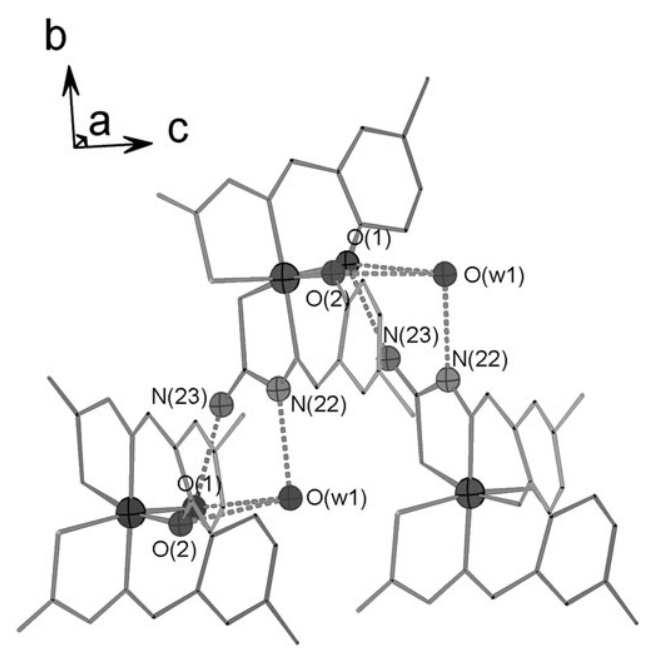

Fig. 6 Strongest intermolecular contacts between complexes at $150 \mathrm{~K}$. 
oxygen atom can be expected from the $\mathrm{O}(1) \cdots \mathrm{N}(23)$ contact. Accordingly, variable temperature FT IR measurements ${ }^{6}$ strongly suggest the presence of hydrogen bonding interac tions (see Fig. S1 in the ESI $\dagger$ ) and that the nature and strength of these interactions are modified during the crystallographic phase transition. We note that the most cooperative process is observed from the conversion of the low temperature lattice, i.e. the phase with the strongest intermolecular contacts. Consequently, the cooperative character of the transition is related to strong elastic interactions ${ }^{20}$ exerted on the LS species, these being partly mediated by the water molecules.

\section{Conclusion}

The crystal structure of $\mathrm{Li}\left[\mathrm{Fe}(5 \mathrm{BrThsa})_{2}\right] \cdot \mathrm{H}_{2} \mathrm{O}$ was deter mined from powder $\mathrm{X}$ ray diffraction data at temperatures corresponding to the LS and HS phases. The spin crossover of $\mathrm{Li}\left[\mathrm{Fe}(5 \mathrm{BrThsa})_{2}\right] \cdot \mathrm{H}_{2} \mathrm{O}$ is concomitant to a first order crystal lographic phase transition. This process takes place without any space group modification. The anionic complexes are implicated in several intermolecular interactions involving $\mathrm{N}$, $\mathrm{O}, \mathrm{Br}$ atoms and the water molecules. The water molecule likely interacts through hydrogen bonds, as evidenced pre viously by IR. A significant variation of the water mediated interactions is detected between the low and the high tem perature phases. Thus, the occurrence of a cooperative process and of a crystallographic phase transition can be related to the existence of a supramolecular network involving water mole cules whose interactions with the ferric units are switched upon the thermal spin crossover process.

Finally, this work confirms that the thiosemicarbazone ferric complexes are good candidates for studying the coop erative spin crossover processes of $\mathrm{Fe}$ (III) and form very attractive building blocks for the elaboration of novel multi functional molecular materials.

\section{Experimental}

\section{Syntheses and characterization}

The ferric complex $\mathrm{Li}\left[\mathrm{Fe}(5 \mathrm{BrThsa})_{2}\right] \cdot \mathrm{H}_{2} \mathrm{O}$, prepared as pre viously described, ${ }^{6}$ was characterized by FT IR, ES MS and elemental analysis. ES MS (MeOH): $m / z \quad 599.9$ (calcd for $\left[\mathrm{Fe}(5 \mathrm{BrThsa})_{2}\right]^{-}:$600.1). Anal. Calcd (Found) for $\mathrm{Li}[\mathrm{Fe}$ (5BrThsa) $\left.)_{2}\right] \cdot \mathrm{H}_{2} \mathrm{O}$ : C 30.75 (30.73); H 2.26 (2.27); N 13.45 (13.27); S 10.26 (10.54); Fe 8.93 (8.32); Li 1.11 (0.93). The magnetic behaviour of $\mathrm{Li}\left[\mathrm{Fe}(5 \mathrm{BrThsa})_{2}\right] \cdot \mathrm{H}_{2} \mathrm{O}$ was determined by a Quantum Design SQUID magnetometer (MPMS5S).

\section{High resolution X-ray diffraction patterns (XDP)}

$\mathrm{X}$ Ray high resolution diffraction patterns were recorded by means of a horizontally mounted INEL cylindrical position sensitive detector (CPS 120) using Debye Scherrer geometry (angular step ca. $0.029^{\circ} 2 \theta$ ). ${ }^{21}$ Monochromatic $\mathrm{Cu} \mathrm{K} \alpha_{1}$ radia tion was selected as incident beam. Low temperature measure ments were achieved with an Oxford Cryosystems $\mathrm{N}_{2}$ cryostream which provides isothermal experiments at different temperatures. The generator power was set to $40 \mathrm{kV}$ and $25 \mathrm{~mA}$. Samples were introduced in $0.5 \mathrm{~mm}$ diameter Lindemann rotating glass capillaries in order to minimize preferential orientations of the crystallites. The time of acquisition was set to seven hours in order to obtain reflections with exploi table intensities. External calibration using $\mathrm{Na}_{2} \mathrm{Ca}_{3} \mathrm{Al}_{2} \mathrm{~F}_{14}{ }^{22}$ cubic phase combined with a low angle calibration using silver behenate $^{23}$ was performed by means of cubic spline fittings.

\section{Structure determination from X-ray powder diffraction}

X-Ray data analyses and indexing. The same strategy was used for both phases. Extraction of the peak positions was performed by means of the WinPLOTR program. ${ }^{24}$ Patterns indexing was carried out with the computer program DIC VOL $04^{25}$ from the twenty unambiguous first lines, with an absolute error on peak positions of $0.03^{\circ}(2 \theta)$. Monoclinic solutions were found with satisfactory figures of merit (see Table 1) and confirmed by successful indexing of all input lines. Systematic absences $(0 k 0, k \quad 2 n+1$ and $h 0 l, l \quad 2 n+$ 1) were consistent with the $P 2_{1} / c$ space group. Adequacy of unit cells and space group was confirmed by structureless whole pattern profile refinements by the Le Bail method ${ }^{26}$ integrated in the FullProf program. ${ }^{27}$

High-spin phase. First calculations were performed with the EXPO $^{28}$ package, integrating EXTRA ${ }^{29}$ for extracting inte grated intensities and SIR $97^{30}$ for direct methods structure solution. A list of 1327 reflections was extracted in the angular range $2.1780^{\circ}(2 \theta)$. According to the degree of diffraction overlap, $16.60 \%$ of these reflections were statistically consid ered as independent. No preferred orientation effects have been found. The two $\mathrm{Br}$ and $\mathrm{Fe}$ atoms were found unambigu ously from the E map with the highest figure of merit. Orientations of the two independent organic moieties were then determined by using the direct space strategy program FOX,${ }^{31}$ choosing the parallel tempering algorithm. The use of 3 objects (two organic molecules and one Fe atom), using starting positions found by SIR97, restricts the number of parameters to 6 ( 3 for the orientation of each organic) in comparison with 78 atomic coordinates corresponding to the 26 remaining atoms of the complex. To avoid objects over lapping, anti bumping restraints (Fe $\mathrm{O}$ and $\mathrm{Fe} \mathrm{N}$ : $1.7 \AA$; Fe S: $1.9 \AA$ A) were applied. Calculations converged in almost $2 \mathrm{~h}$ to the expected solution. The corresponding atomic coordinates were used as the starting model for Rietveld refinement, using the FullProf ${ }^{27}$ program integrated in Win PLOTR $^{24}$ software. A pseudo Voigt function was selected to describe individual line profiles. In order to describe the angular dependence of the peak full width at half maximum, the usual quadratic function in $\tan \theta$ was used. Unit cell and instrumental parameters were allowed to vary from time to time during the refinement process, as well as atomic coordi nates with soft distance and angular restraints. At this stage of the refinement, the structural model indicators converged to $R_{\mathrm{I}} \quad 0.174$ and $R_{\mathrm{F}} \quad 0.084$, which confirmed the validity of the starting structural hypothesis. Difference Fourier calcula tions were then undertaken by using SHELXL ${ }^{32}$ and revealed unambiguously the water molecule.

Low-spin phase. The same softwares were used to solve the structure of the LS phase. According to the degree of 
diffraction overlap, $20.24 \%$ of the 1283 reflections extracted in the angular range $2.1780^{\circ}(2 \theta)$ were statistically considered as independent and used for direct methods calculations. The $\mathrm{Br}$ and $\mathrm{Fe}$ atoms with four donor atoms ( $\mathrm{S}$ and $\mathrm{O}$ atoms) were found from the E map with the highest figure of merit. The same three objects were considered in the Fox program. As for the HS phase, bromide atoms were first used as pivot atoms for organic moieties, but calculations never converged, due to some inaccuracy on their positions. Organic molecules were then allowed to rotate around sulfur atoms instead of the bromide atom and calculations converged rapidly to the correct structural model. The water molecule was also loca lized by difference Fourier calculations alternating with Rietveld refinement cycles.

Final Rietveld refinements. Final Rietveld refinements (see Table 1) carried out in angular ranges $2.1770^{\circ}(2 \theta)$ and $3.1879 .5^{\circ}(2 \theta)$ used 946 and 1253 reflections for the HS and LS phase, respectively. They involved the following para meters: 90 atomic coordinates, 1 scale factor, 1 zero point, 4 cell parameters and 2 half width parameters for both phases. One variable for $\eta$ was refined for the HS phase and 2 asymmetry factors were also considered for the BS phase. Soft distances and angular restraints were maintained for ligands in both phases. Background has been treated as linear interpola tion between 39 and 34 given points for high and low temperature phases, respectively. As a first convergence criter ion, the metal ligand bond lengths were allowed to slightly vary around the average values reported in literature for HS and LS species. ${ }^{9-13}$ Attempts to localize the $\mathrm{Li}^{+}$cations were not undertaken. Indeed, lithium scattering strength is insig nificant compared to the ferric complex. Moreover, last dif ference Fourier calculations undertaken for the both phases confirms that no additional atom can be localized. Fig. 2 shows the final fits obtained between calculated and observed patterns. They correspond to satisfactory crystal structure model indicators and profile factors $\left(R_{\mathrm{I}}\right.$ and $R_{\mathrm{F}}$, see Table 1$)$. In powder diffraction, the $R_{\mathrm{p}}$ and $R_{\mathrm{wp}}$ factors are not the most relevant factors to confirm the validity of the fits. Indeed, in our study for example, it is clear that $R_{\mathrm{p}}$ and $R_{\mathrm{wp}}$ are "artificially" lowered by high background levels. Nevertheless, $R_{\mathrm{I}}$ and $R_{\mathrm{F}}$ values are satisfactory (less than $10 \%$ ) and the $R_{\mathrm{I}} / R_{\mathrm{F}}$ ratios are lower than 1.5 , indicating that structural models are complete. These values demonstrate the accuracy of the two structural models. Finally, structureless whole pattern profile refinements have been undertaken at 150 and $373 \mathrm{~K}$ (see Fig. S3 in the ESI $\dagger$ ). The difference curves are not significantly improved compared to the Rietveld refinement, which confirms the accuracy of the present structural models. CCDC reference numbers 617382 and 617383. For crystal lographic data in CIF or other electronic format see DOI: $10.1039 / \mathrm{b} 605326 \mathrm{~b}$

\section{Acknowledgements}

We thank Dr Michel Gasgnier for preliminary investigations and Dr Xavier Ottenwaelder for help in the preparation of the revised version of this manuscript. Financial support from the European Union (TOSS TMR, Contract ERB FMRX CT98
0199) and (MAGMANet NoE, Contract NMP3 CT 2005 515767 2) are gratefully acknowledged.

\section{References}

1 (a) L. Cambi and A. Cagnasso, Atti. Accad. Naz. Lincei, Cl. Sci. Fis. Mat. Nat. Rend., 1931, 13, 809; (b) L. Cambi and L. Szego, Ber. Dtsch. Chem. Ges., 1931, 64, 167.

2 (a) Topics in Current Chemistry, Spin Crossover in transition metal compounds, ed. P. Gutlich and H. A. Goodwin, Springer, Berlin, 2004, vol. 233 235; (b) O. Kahn, Molecular Magnetism, VCH, New York, 1993

3 P. Gutlich, A. Hauser and H. Spiering, Angew. Chem., Int. Ed. Engl., 1994, 33, 2024.

4 P. J. van Koningsbruggen, Y. Maeda and H. Oshio, in Spin Crossover in Transition Metal Compounds I, Topics in Current Chemistry, ed. P. Gutlich and H. A. Goodwin, Springer, Berlin, 2004, vol. 233, pp. 259324.

5 W. R. Sheidt and C. A. Reed, Chem. Rev., 1981, 81, 543.

6 S. Floquet, M. L. Boillot, E. Rivière, F. Varret, K. Boukheddaden, D. Morineau and P. Négrier, New J. Chem., 2003, 27, 341348.

7 (a) V. V. Zelentsov, Sov. Sci. Rev. Sect. B, Chem., 1987, 10, 485; (b) V. V. Zelentsov, Sov. J. Coord Chem., 1992, 18, 787; (c) M. D. Timken, S. R. Wilson and D. N. Hendrickson, Inorg. Chem., 1985, 24, 3450; (d) M. Mohan, P. H. Madhuranath, A. Kumar and N. K. Jha, Inorg. Chem., 1989, 28, 96; (e) N. S. Gupta, M. Mohan, N. K. Jha and W. E. Antholine, Inorg. Chim. Acta, 1991, 184, 13.

8 V. V. Zelentsov, L. G. Bogdanova, A. V. Ablov, N. V. Gerbeleu and C. V. Dyatlova, Russ. J. Inorg. Chem. (Engl. Trans.), 1973, 18, 1410.

9 N. A. Ryabova, V. I. Ponomarev, V. V. Zelentsov and L. O. Atovmyan, Sov. Phys. Crystallogr. (Engl. Transl.), 1981, 26, 5357.

10 N. A. Ryabova, V. I. Ponomarev, V. V. Zelentsov, V. I. Shipilov and L. O. Atovmyan, J. Struct. Chem. (Engl. Transl.), 1981, 22, 234.

11 N. A. Ryabova, V. I. Ponomarev, L. O. Atovmyan, V. V. Zelentsov and V. I. Shipilov, Sov. J. Coord. Chem. (Engl. Transl.), 1978, 4, 95.

12 N. A. Ryabova, V. I. Ponomarev, V. V. Zelentsov and L. O. Atovmyan, Sov. Phys. Crystallogr. (Engl. Transl.), 1982, 27, 171175.

13 (a) N. A. Ryabova, V. I. Ponomarev, V. V. Zelentsov and L. O. Atovmyan, Sov. Phys. Crystallogr. (Engl. Transl.), 1982, 27, 46 52; (b) N. A. Ryabova, V. I. Ponomarev, V. V. Zelentsov and L. O. Atovmyan, Dokl. Chem. (Engl. Transl.), 1981, 259, 715719.

14 S. Floquet, PhD Thesis, University of Paris XI, 2001.

15 K. D. M. Harris, M. Tremayne and B. M. Kariuki, Angew. Chem., Int. Ed., 2001, 40, 1626.

16 S. Hayami, Z. Z. Gu, M. Shiro, Y. Einaga, A. Fujishima and O. Sato, J. Am. Chem. Soc., 2000, 122, 71267127.

17 (a) E. Konig, Prog. Inorg. Chem., 1987, 35, 527; (b) P. Guionneau, C. Brigouleix, Y. Barrans, A. E. Goeta, J. F. Létard, J. A. K. Howard, J. Gaultier and D. Chasseau, C. R. Acad. Sci., Ser. IIc: Chim., 2001, 4, 161 171; (c) P. Guionneau, J. F. Létard, D. S. Yufit, D. Chasseau, G. Bravic, A. E. Goeta, J. A. K. Howard and O. Kahn, J. Mater. Chem., 1999, 9, 985994.

18 (a) J. F. Létard, P. Guionneau, L. Rabardel, J. A. K. Howard, A. E. Goeta, D. Chasseau and O. Kahn, Inorg. Chem., 1998, 37, 4432 4441; (b) A. M. Greenaway and E. Sinn, Inorg. Chem., 1978, 100, 8080 8084; (c) P. Gutlich, H. Koppen and H. G. Steinhauser, Chem. Phys. Lett., 1980, 74, 475.

19 (a) H. Oshio, K. Toriumi, Y. Maeda and Y. Takashima, Inorg. Chem., 1991, 30, 4252 4260; (b) A. J. Conti, R. K. Chadha, K. M. Sena, A. L. Rheingold and D. N. Hendrickson, Inorg. Chem., 1993, 32, 2670 2680; (c) A. J. Conti, K. Kaji, Y. Nagano, K. M. Sena, Y. Yumoto, R. K. Chadha, A. L. Rheingold, M. Sorai and D. N. Hendrickson, Inorg. Chem., 1993, 32, 26812693.

20 H. Spiering, in Spin Crossover in Transition Metal Compounds I Topics in Current Chemistry, ed. P. Gutlich and H. A. Goodwin, Springer, Berlin, 2004, vol. 235, pp. 171195.

21 J. Ballon, V. Comparat and J. Pouxe, Nucl. Instrum. Methods, 1983, 217, 213. 
22 M. Evain, P. Deniard, A. Jouanneaux and R. Brec, J. Appl. Crystallogr., 1993, 26, 563.

23 T. C. Huang, H. Toraya, T. N. Blanton and Y. Wu, J. Appl. Crystallogr., 1993, 26, 180.

24 T. Roisnel and J. Rodriguez Carvajal, Mater. Sci. Forum, 2001, $378381,118$.

25 A. Boultif and D. Louer, J. Appl. Crystallogr., 2004, 37, 724.

26 A. Le Bail, H. Duroy and J. F. Fourquet, Mater. Res. Bull., 1988, 23, 447.

27 J. Rodriguez Carvajal, Collected Abstracts of Powder Diffraction Meeting, Toulouse, France, 1990.
28 A. Altomare, M. C. Burla, M. Camalli, B. Carrozzini, G. L. Cascarano, C. Giacovazzo, A. Guagliardi, A. G. G. Moliterni, G. Polidori and R. Rizzi, J. Appl. Crystallogr., 1999, 32, 339.

29 A. Altomare, M. C. Burla, G. Cascarano, C. Giacovazzo, A. Guagliardi, A. G. G. Moliterni and G. Polidori, J. Appl. Crystallogr., 1995, 28, 842.

30 A. Altomare, M. C. Burla, M. Camalli, G. L. Cascarano, C. Giacovazzo, A. Guagliardi, A. G. G. Moliterni, G. Polidori and R. Spagna, J. Appl. Crystallogr., 1999, 32, 115.

31 V. Favre Nicollin and R. Cerny, J. Appl. Crystallogr., 2002, 35, 734.

32 G. M. Sheldrick, SHELXL97, University of Gottigen, Germany, 1997. 